Article

\title{
Preparation of a Series of Pd@UIO-66 by a Double-Solvent Method and Its Catalytic Performance for Toluene Oxidation
}

\author{
Chuanying Wei, Haili Hou, Ermo Wang and Min Lu *(1) \\ School of Chemical Engineering, Northeast Electric Power University, Jilin 132000, China; \\ 13844204685@163.com (C.W.); h18704329087@163.com (H.H.); asdfg8596@126.com (E.W.) \\ * Correspondence: lumin19770919@163.com; Tel.: +86-1357-851-1861
}

Received: 26 November 2019; Accepted: 20 December 2019; Published: 23 December 2019

\begin{abstract}
This paper reports on the preparation, characterization, and catalytic properties of the Pd@UIO-66 for toluene oxidation. The samples are prepared by the double-solvent method to form catalysts with large specific surface area, highly dispersed $\mathrm{Pd}^{0}$ (Elemental palladium) and abundant adsorbed oxygen, which are characterized by X-ray Photoelectron Spectroscopy (XPS), Brunauer-Emmett-Teller (BET) and Transmission Electron Microscopy (TEM). The results show that as the Pd content increases, the adsorbed oxygen content further increases, but at the same time $\mathrm{Pd}^{0}$ will agglomerate and lose some active sites, which will affect its catalytic performance. While $0.2 \%$ Pd@UIO-66 has the highest concentration of $\mathrm{Pd}^{0}$, the result shows it has the best catalytic activity and the $\mathrm{T}_{90}$ temperature is $210^{\circ} \mathrm{C}$.
\end{abstract}

Keywords: Toluene oxidation; Pd@UIO-66; Double-solvent method

\section{Introduction}

Volatile Organic Compounds (VOCs) are a series of substances that have a negative impact on the environment, mainly from vehicle emissions and industrial production [1-5]. Among many organic substances, toluene has attracted attention as one of the most widely affected volatile organic compounds [6]. Humans have already invented many methods to control them since recent decades. Among these methods, the combustion catalysis is the simplest and most feasible [7-10]. The combustion catalysis is the deep degradation of VOCs to $\mathrm{CO}_{2}$ and $\mathrm{H}_{2} \mathrm{O}$ at low temperatures $\left(200-500{ }^{\circ} \mathrm{C}\right.$ ) by means of a catalyst [11] and catalysts play a vital role in combustion catalysis. At this stage, catalysts are mainly divided into supported noble metal catalysts (SNMCs) and supported transition metal catalysts (TMOs). Compared with TOMs, SNMCs have a better low temperature activity and easy regeneration. Noteworthy, the supported Pd materials are most widely investigated, which is probably due to the fact that it can make VOCs destroyed more easily at low temperatures [12-15].

For Pd-based catalysts, the dispersion of the active ingredient and the interaction with the support are especially critical for catalytic efficiency $[16,17]$; therefore, research on the support is very important. In addition, the supports in the Pd material are usually $\mathrm{SiO}_{2}$ and $\gamma-\mathrm{Al}_{2} \mathrm{O}_{3}$, but molecular sieves and metal oxides are used as well, including ZSM-5, SBA-15, $\mathrm{TiO}_{2}$, and $\mathrm{CeO}_{2}$, to enhance the dispersion of active sites and aid reactant adsorption [17-21]. Therefore, to some extent, the supports with large specific surface area and strong adsorption will be more helpful to the performance of Pd.

Metal-organic frameworks (MOFs) are emerging materials with surprising specific surface area, adjustable pore structure and high concentration of metal ions, which are mainly used in gas adsorption and separation, sensors, and catalysis in many fields [22-25]. Among many series of materials, the UIO-66 is a metal-organic framework with $\mathrm{Zr}$ as the metal center and terephthalic acid as the 
organic ligand; it has a large specific surface area and a developed pore structure, is easy to chemically functionalize, and has excellent mechanical stability and heat resistance. Due to the above characteristics, UIO-66 and its derived UIO-66 series have received extensive attention in the field of catalysis. As a support for Pd, the UIO-66 is mainly used in Suzuki-Miyaura coupling reaction, hydrogenation catalysis and catalytic upgrading, etc. [23,26,27]. Luz et al. [28] apply the Pd@UIO-66-type to selective hydrogenation catalysis. The structure of UIO-66 combined with chemical vapor infiltration forms Pd-Nano particles (NPs), providing the efficiently selective activity. Jiang and co-workers [23] prepare UIO-66 sealed nano-palladium for efficient and continuous catalytic upgrade of ethanol to n-butanol. The close synergy between highly dispersed $\mathrm{Pd}$ and unsaturated $\mathrm{Zr}$ sites is the reason of high activity. Through the above reports, it can be found that the preparation method of Pd@UIO-66 needs to follow strict conditions, and $\mathrm{Xu}$ et al. [29] realize the simple preparation of Pd@MOF by the double-solvent method, which uses hydrophilic pores of MOFs. The double-solvent include the hydrophilic solvent (water) and the hydrophobic solvent (n-hexane). The former disperses the metal precursor, the volume is less than or equal to the pore volume, and it can be absorbed by the hydrophilic pores, while the latter provides the suspension adsorbent and promotes the impregnation. The result of this simple method is the reduction of deposits on the outer surface. Using the pore space of MOFs to better disperse Pd, this method is beneficial to the formation of noble metal NPs. Few studies have investigated the uses of Metal-organic frameworks (MOFs) impregnated with noble metals for the catalytic oxidation of volatile organic compounds. As a support, MOFs can improve the dispersion and enhance adsorption of NPs. Therefore, Pd@UIO-66 application may have the amazing performance in the VOCs catalysis.

In this research, Pd@UIO-66 was prepared as a catalyst by the double-solvent method, and its feasibility and catalytic efficiency as a new catalytic material in the catalytic reaction of toluene were studied. The stability and durability of the catalyst were also evaluated. Correspondingly, the relationship between catalyst structure and catalyst activity is characterized the material by $\mathrm{N}_{2}$ adsorption-desorption isotherm, and the data for analysis was obtained using the Brunauer-Emmett-Teller (BET) model, X-ray Diffraction (XRD), Transmission Electron Microscopy (TEM), X-ray Photoelectron Spectroscopy (XPS), and Fourier Transform Infrared Spectroscopy(FTIR).

\section{Materials and Methods}

\subsection{Preparation of Catalysts}

Preparation of UIO-66: In this study, the UIO-66 was prepared from the hydrothermal method in accordance with the procedure reported by $\mathrm{H}$. Wu et al [30]. The standard MOFs hydrothermal synthesis was performed by dissolving $\mathrm{ZrCl}_{4}(0.053 \mathrm{~g}, 0.227 \mathrm{mmol})$ and terephthalic acid $(0.034 \mathrm{~g}, 0.227 \mathrm{mmol}$ of $\mathrm{H}_{2} \mathrm{BDC}$ ) in N,N-dimethylformamide (24.9 g, $340 \mathrm{mmol}$ of DMF) at the room temperature with sufficient agitation to obtain a mixture. The mixture was transferred to a $100 \mathrm{~mL}$ polytetrafluoroethylene reactor and reacted at $120^{\circ} \mathrm{C}$ for $24 \mathrm{~h}$. After cooling to room temperature, the white precipitate was filtered, then washed repeatedly with DMF and methanol, finally dried at $100{ }^{\circ} \mathrm{C}$ to obtain a white product.

Preparation of Pd@UIO-66: Pd@UIO-66 synthesis adopts the double-solvent method, and the hydrophilicity of the MOFs cavity is used to disperse Pd on the inner surface as much as possible, thereby improving the use efficiency of the support and increasing the dispersion degree of the active ingredient. $0.5 \mathrm{~g}$ UIO-66 were dispersed in $100 \mathrm{~mL}$-hexane and sonicated for $1 \mathrm{~h}$. In addition, $0.1875 \mathrm{~mol} / \mathrm{L}$ aqueous solution of palladium nitrate was used as a precursor to prepare elemental palladium $\left(\mathrm{Pd}^{0}\right) .12 \mu \mathrm{L}$ Palladium nitrate solution was dropwise added to the dispersed UIO-66 in hexane and stirred for $2 \mathrm{~h}$, then dried at the room temperature. The solid was dried in a vacuum drying oven at $100{ }^{\circ} \mathrm{C}$, transferred to a tube furnace, and reduced at $200{ }^{\circ} \mathrm{C}$ for $5 \mathrm{~h}$ in a 10 vol \% $\mathrm{H}_{2} / \mathrm{N}_{2}$ atmosphere to obtain $0.1 \mathrm{wt} \% \mathrm{Pd} @ \mathrm{UIO}-66$, hereinafter referred to as $0.1 \% \mathrm{Pd} @ \mathrm{U}, 0.2 \% \mathrm{Pd} @ \mathrm{U}$, 1\% Pd@U and 2\% M@U materials were prepared according to the above method. 


\subsection{Catalyst Characterization}

XRD patterns were recorded on a Rigaku Smart Lab 9kW diffractometer (Tokyo, Japan)with Cu-K $\alpha$ radiation $(\lambda=1.5418 \AA)$ in the $5-55^{\circ}$ range with a step size of $0.02^{\circ} . \mathrm{N}_{2}$ adsorption-desorption isotherms were performed at $77 \mathrm{~K}$ on a micromeritics ASAP 2460 instrument (Micromeritics, Norcross, GA, USA) in a static mode; all samples were degassed at $623 \mathrm{~K}$ for $4 \mathrm{~h}$. The specific surface area was calculated by the BET equation, and the pore volume and average pore diameter were calculated based on the Barrett-Joyner-Halenda (BJH) method. XPS measurements were performed on Thermo Fisher Scientific Esca Lab 250Xi instrument (Shanghai, China). The peak positions were corrected by using the containment carbon $(\mathrm{C} 1 \mathrm{~s}$ peak $=284.8 \mathrm{eV})$. Changes in the organic framework of the material were characterized by FTIR and experiments were performed on a Nicolet iS50 FTIR spectrometer (Shanghai, China). An inductively coupled plasma optical emission spectrometer (ICPOES, Optima 2000DV, MA, USA) was employed to determine the overall Ce content in the prepared catalyst.

\subsection{Catalytic Activity Measurement}

The catalytic combustion of VOCs was carried out in a fixed-bed quartz reactor using a $0.10 \mathrm{~g}$ catalyst of 40-60 mesh. The reactant mixture contained $1000 \mathrm{ppm}$ toluene and $20 \mathrm{vol} \% \mathrm{O}_{2}$ balanced in $\mathrm{N}_{2}$ (balance gas) with a total flow of $100 \mathrm{~mL} \mathrm{~min}^{-1}$, giving a GHSV of $60,000 \mathrm{~mL}(\mathrm{~g} \cdot \mathrm{h})^{-1}$. Before the start of each experiment, the catalyst needs to be pretreated for $1 \mathrm{~h}$ in the real reaction gas in order to overcome the overestimation caused by toluene adsorption. A gas chromatograph (Agilent 7890A) equipped with a flame ionization detector (FID, using a column of Porapack-Q/molecular sieve5A, $2 \mathrm{~m}$ in length) and a thermal conductivity detector (TCD, using a column of RT-QPlotdivinylbenzene PLOT, $30 \mathrm{~m}$ in length) were used to monitor the trend of the toluene concentration online (Scheme S1). The toluene conversion (\%) was calculated according to the following equation:

$$
\text { Toluene conversion }=\frac{[\text { Toluene }]_{\text {in }}-[\text { Toluene }]_{\text {out }}}{[\text { Toulene }]_{\text {in }}} \times 100 \%
$$

Arrhenius plots the activation energy from the toluene rate of the sample.

\section{Results and Discussion}

\subsection{Material Structure and Physical—Chemical Properties}

Figure 1 represents the Pd@UIO-66 catalyst prepared by UIO-66 as a support at $\mathrm{N}_{2}$ adsorption-desorption isotherm at $77 \mathrm{~K}$. All solids exhibit a microporous structure. Obviously, at 1\% Pd@U and 2\% Pd@U, the $\mathrm{N}_{2}$ adsorption volume rises sharply and exhibits a relatively large hysteresis loop at very low relative pressure [31,32]. The $\mathrm{N}_{2}$ adsorption-desorption isotherm curve of UIO-66 is collected in Figure S2. The value of the pore volume in Table S1 can reflect this phenomenon more clearly. The pore volume and specific surface area of $0.1 \%$ Pd@U and $0.2 \%$ Pd@U are much larger than 1\% Pd@U and 2\% Pd@U. The former is close to the data of pure UIO-66. Although the specific surface area and pore volume differed greatly, there was no significant change in the pore size of the sample, which indicates that the double-solvent method is mild to the UIO-66 structure and does not affect its basic microporous structure. The larger specific surface area, the more favorable for toluene catalysis, so low loading of $0.1 \%$ Pd@U and $0.2 \%$ Pd@U may have better catalytic efficiency relative to high load samples [33].

The XRD patterns of UIO-66 and Pd@UIO-66 are shown in Figure 2. It can be seen that UIO-66 has obvious peaks, which is consistent with previous reports [34], which also shows that UIO-66 has the excellent crystallinity. As shown in Figure 2, the Pd@UIO-66 diffraction peak is the same as UIO-66, and the diffraction peak of Pd is not observed, which indicates that the Pd NPs content is low, and the dispersion is high, which is well wrapped by the pores of UIO-66 [29]. However, there is an interesting phenomenon that the diffraction peaks of the 1\% Pd@U and 2\% Pd@U samples are 
significantly broadened, which indicates that although the two samples have a further effect on the crystallinity of UIO-66 due to the further increase in Pd content. Obviously, the double-solvent method as a mild preparation method does not affect the crystal structure and the basic microporous structure of UIO-66, and greatly retains the structural characteristics of UIO-66 as a support.

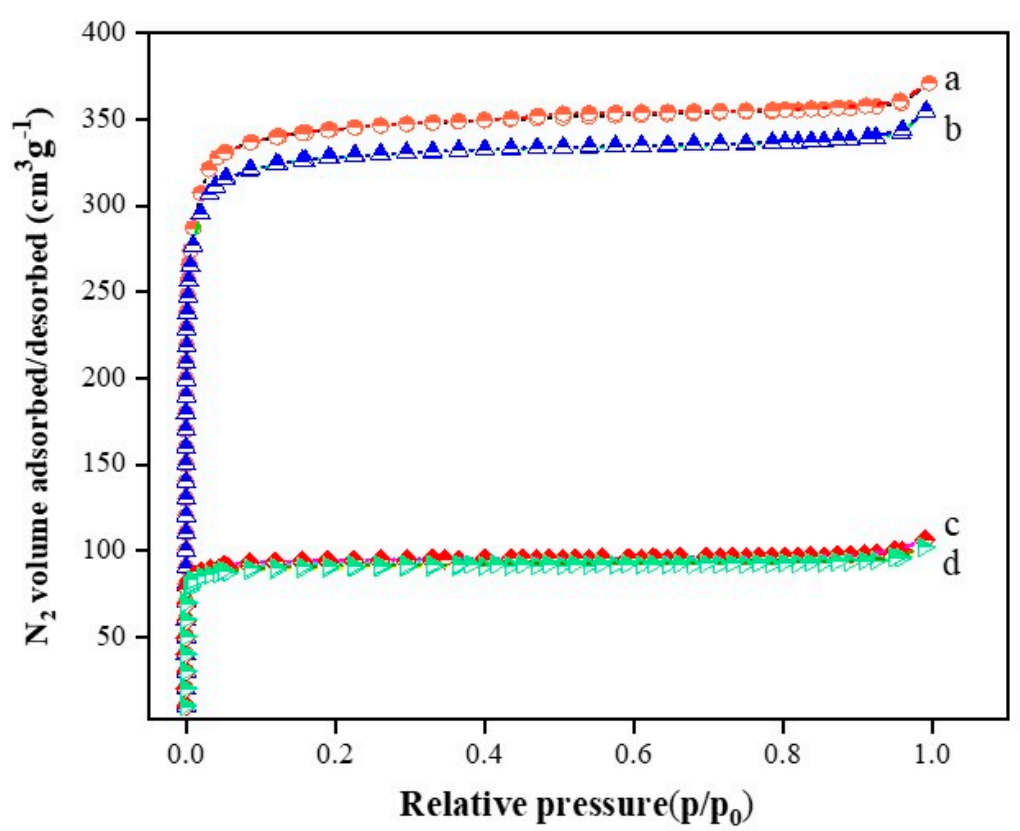

Figure 1. $\mathrm{N}_{2}$ adsorption/desorption analysis of (a) $0.1 \%$ Pd@U (b) $0.2 \%$ Pd@U (c) $1 \%$ Pd@U (d) $2 \%$ Pd@U.

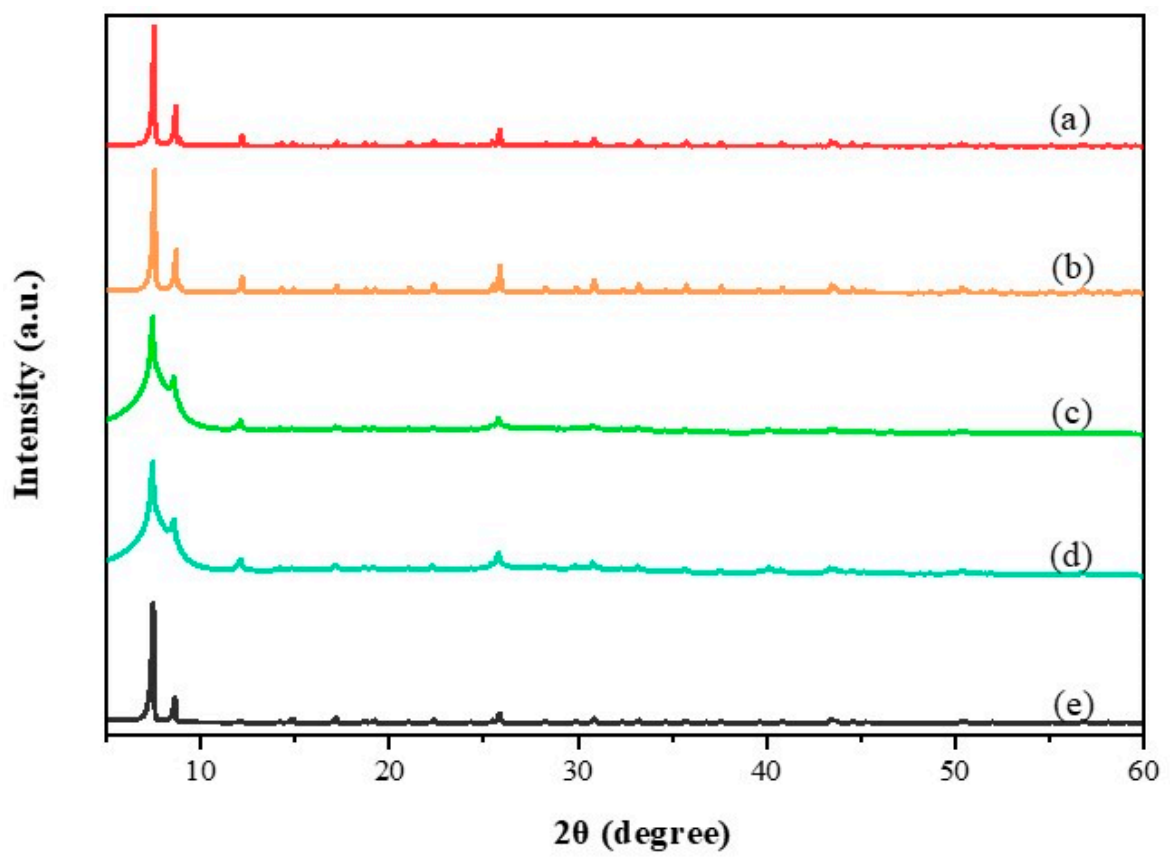

Figure 2. XRD patterns of (a) 0.1\% Pd@U (b) 0.2\% Pd@U (c) 1\% Pd@U (d) 2\% Pd@U (e) UIO-66.

The structure and the Pd distribution of the Pd@UIO-66 catalysts were analyzed by TEM microscopy. Figure 3a-d shows TEM images of 0.1\% Pd@U to 2\% Pd@U catalyst, respectively. The Pd particle image appears as black spots, appears to be scattered and spherical $[18,23]$. It can be found that as the palladium concentration increases, the size of NPs also increases. It is worth noting that as the metal palladium concentration increases, larger particles of Pd NPs appear in the $1 \%$ and $2 \%$ samples, and it can be observed from Figure $3 c, d$ that the majority of the particles are located on the outer 
surface of the material. This may be detrimental to the catalytic performance of the material. For low concentration load samples, the large surface area of UIO-66 combined with the introduction of Pd by the double-solvent method not only forms highly dispersing of Pd NPs, but also disperses Pd in a large amount on the inner surface of UIO-66, which will improve the specific surface area use of metal particles [23]. Highly dispersed Pd NPs have a major positive impact on the catalytic performance of toluene.

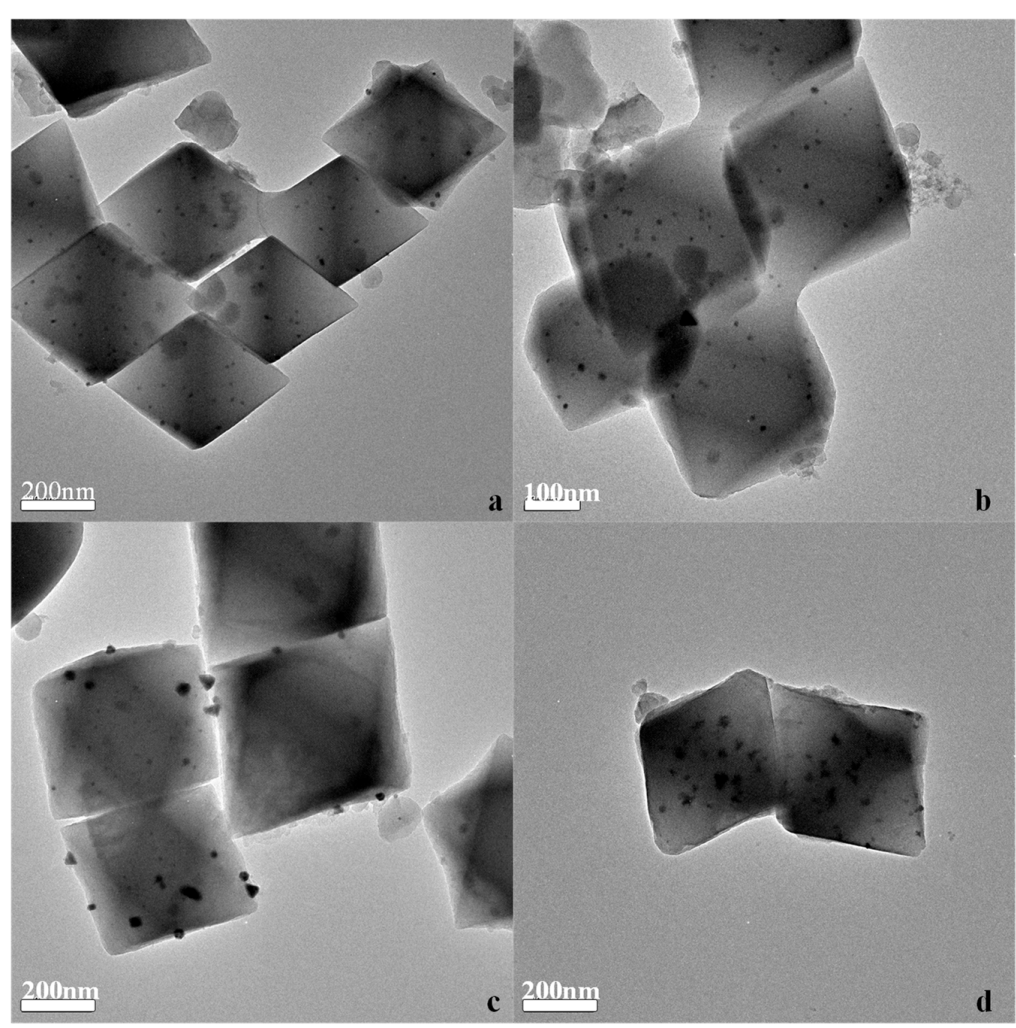

Figure 3. TEM images of (a) 0.1\% Pd@U (b) 0.2\% Pd@U (c) 1\% Pd@U (d) 2\% Pd@U.

To further understand the chemical states of Pd and O on the surface of Pd@UIO-66, XPS characterization was performed (Figure 4 and Table S2). The binding energy values of Pd3d $\mathrm{d}^{3 / 2}$ are shown in Figure 4A, and $\mathrm{Pd}^{0}(333.38-333.57 \mathrm{eV})$ and $\mathrm{Pd}^{2+}(335.28-335.85 \mathrm{eV})$ were observed [12,17]. At the same time, after comparing among the four samples, it can be found that as the Pd content increases, the binding energy migrates to high energy. For palladium species, the metal palladium site is very active in the decomposition of VOCs, so it plays an important role in adsorbing and decomposing toluene to form various secondary products such as benzaldehyde and benzoic acid. Correspondingly, $\mathrm{PdO}$ provides an additional surface oxygen source that is more susceptible to oxidation of secondary products. Finally, the toluene is completely oxidized to $\mathrm{CO}_{2}$ and $\mathrm{H}_{2} \mathrm{O}$ [35-37]. In this regard, the $0.2 \%$ $\mathrm{Pd} @ \mathrm{U}$ sample with the highest $\mathrm{Pd}^{0}$ ratio (95.13\%) may be beneficial to the catalytic direction of toluene.

As shown in Figure 4B, in the $530.10-530.18 \mathrm{eV}$ interval is lattice oxygen, $531.85-531.91 \mathrm{eV}$ is adsorbed oxygen. In addition, a high concentration of adsorbed oxygen is exhibited, which is attributed to the fact that the oxygen-rich group in the UIO-66 material adsorbs to the unsaturated $\mathrm{Zr}-\mathrm{O}$ site and forms adsorbed oxygen under certain conditions. In addition, as the concentration of palladium increases, the concentration of adsorbed oxygen is in an ascending order $(2 \% \mathrm{Pd} @ \mathrm{U}>1 \% \mathrm{Pd} @ \mathrm{U}>$ 0.2\% Pd@U > 0.1\% Pd@U) [23]. The binding energy image of Zr3d is collected in Figure S1. It can be observed from the figure that the binding energy of $\mathrm{Zr}$ shifts toward high energy, which indicates that as the palladium increases, the outer electrons of Zr decrease. Among them, 0.2\% Pd@U sample has the highest binding energy of $\mathrm{Pd}, \mathrm{Zr}$ and lattice oxygen relative to other materials. Generally, this is 
due to the strong electronic interaction between $\mathrm{Pd}-\mathrm{O}-\mathrm{Zr}$ which promotes electron transfer between the active ingredient and the support [38].

The oxidation mechanism of Pd species is mainly the L-H (Langmuir-Hinshelwood) model, i.e., the two reactants are simultaneously adsorbed on the same active site for reaction. $\mathrm{Pd}^{0}$ acts as an active site for the adsorption and dissociation of toluene, while a high concentration of adsorbed oxygen helps to continue to oxidize the decomposed material to form $\mathrm{H}_{2} \mathrm{O}$ and $\mathrm{CO}_{2}[14,39]$. Therefore, the content of $\mathrm{Pd}^{0}$ is more critical for the first decomposition of toluene relative to the oxygen concentration. Moreover, the oxidation mechanism of the Pd catalyst generally follows the L-H model [40]. As such, in the presence of high concentrations of $\mathrm{Pd}^{0}$, high concentrations of adsorbed oxygen reactions are advantageous for the reaction.
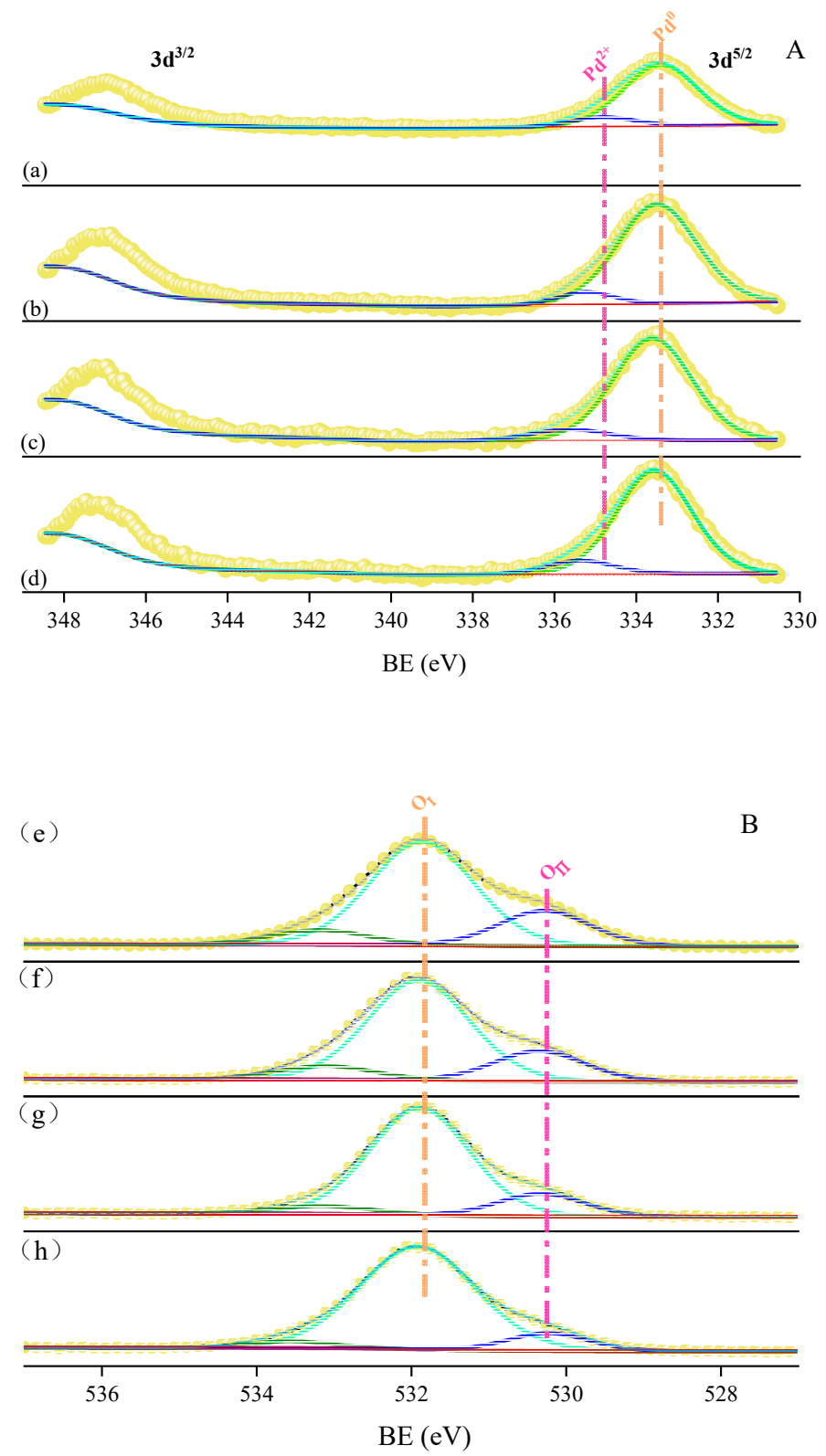

Figure 4. XPS spectra of (A) Pd3d (a) 0.1\% Pd@U (b) 0.2\% Pd@U (c) 1\% Pd@U (d) 2\% Pd@U.And (B) O1s (e) $0.1 \%$ Pd@U (f) $0.2 \%$ Pd@U (g) 1\% Pd@U (h) 2\% Pd@U. 


\subsection{Catalytic Performance}

In the current study, the performance of the catalyst is tested by a toluene-catalyzed oxidation reaction in the range of $170-270{ }^{\circ} \mathrm{C}$. The blank experiment catalyzed pure UIO-66 without metals using toluene. The activity is not satisfactory, and the catalytic performance is always lower than $10 \%$ in the reaction temperature range (Figure S3). The activity was proposed in Figure 5A. Toluene was completely oxidized to water and carbon dioxide by each sample, and no other by-products were found during the reaction, which explained that the system maintains a $99.5 \%$ carbon balance in each run. It can be seen intuitively that all four catalysts have typical S-shaped curve activity, and the toluene catalytic concentration is also enhanced with the increasing temperature. The $\mathrm{T}_{50}$ and $\mathrm{T}_{90}$ temperatures of the four catalysts are collected in Table S3. For 0.1\% Pd@U, 0.2\% Pd@U, 1\% Pd@U and 2\% Pd@U, the $\mathrm{T}_{50}$ values are $232,210,236$ and $238{ }^{\circ} \mathrm{C}$ and the $\mathrm{T}_{90}$ values are $238,217,246$ and $249{ }^{\circ} \mathrm{C}$, respectively. Therefore, the catalytic activity of toluene oxidation increased in the following order: $2 \%$ Pd@U < 1\% Pd@U < 0.1\% Pd@U < 0.2\% Pd@U. This fact indicates that the catalytic efficiency of Pd-based SNMCs is affected by $\mathrm{Pd}^{0}$ and $\mathrm{O}$. The high concentration and high dispersion of $\mathrm{Pd}^{0}$ provide abundant adsorption sites and accelerate the decomposition of toluene. This can explain that 1\% Pd@U has a high concentration of $\mathrm{Pd}^{0}$ but the activity is less than $0.1 \% \mathrm{Pd} @ \mathrm{U}$. The apparent activation energy of each sample was calculated through the Arrhenius curve and is shown in Figure 5B. To prevent the sample from being affected by internal diffusion, the interval was selected below $20 \%$ to plot the Arrhenius curve and the apparent activation energies of each sample was calculated to be $76.88 \mathrm{~kJ} \mathrm{~mol}^{-1}(0.1 \%$ Pd@U), $69.84 \mathrm{~kJ} \mathrm{~mol}^{-1}$ (0.2\% Pd@U), $85.18 \mathrm{~kJ} \mathrm{~mol}^{-1}$ (1\% Pd@U) and $87.56 \mathrm{~kJ} \mathrm{~mol}^{-1}$ (2\% Pd@U). The data corresponds to the catalytic oxidation performance of the sample, $0.2 \%$ has the lowest activation energy and is the best activity, which also corresponds to the previous characterization.
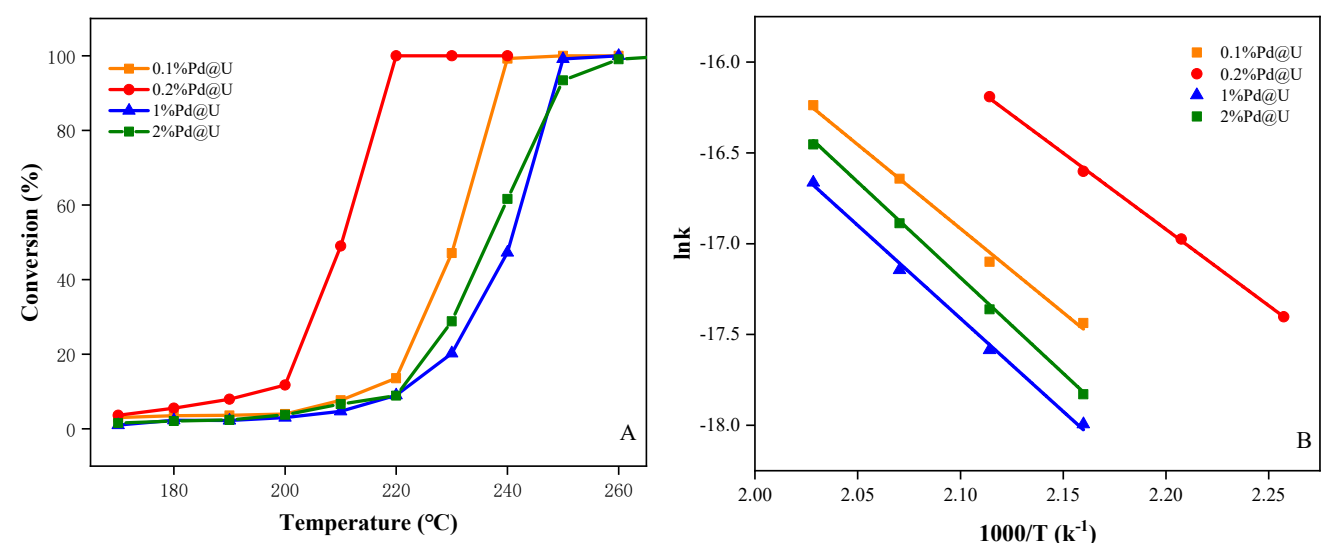

Figure 5. (A) Toluene conversion and (B) Arrhenius plots for toluene oxidation over the samples under the conditions of toluene concentration $=1000 \mathrm{ppm}, 20 \mathrm{vol} \% \mathrm{O}_{2}$, and WHSV $=60,000 \mathrm{~mL}(\mathrm{~g} \cdot \mathrm{h})^{-1}$.

\subsection{Stability and Durability Test}

It was observed by XRD image (Figure S4) that there was no change in the characteristic diffraction peak of UIO-66 before or after the reaction. In addition, the specific organic framework changes were exhibited by FTIR (Figure S5), the characteristic peak of the carbon-oxygen double bond of the carboxyl group at $1661 \mathrm{~cm}^{-1}$, the absorption peak of $1575 \mathrm{~cm}^{-1}$ and $1393 \mathrm{~cm}^{-1}$ is COO-, the characteristic peak of the benzene ring is $1500 \mathrm{~cm}^{-1}$, and the vibration peak of $749 \mathrm{~cm}^{-1}$ is derived from the vibration of $\mathrm{Zr-O}$ [41]. It was found that the carboxyl group was slightly red-shifted after the reaction, indicating that partial deligandation, which was attributed to the removal of some of the coordination functional groups by UIO-66 at high temperatures. However, the other relatively basic structure has not changed, which indicates that the basic structure of the material remains stable at the reaction temperature, which is consistent with the XRD data [42,43]. The stability and durability of the catalyst were evaluated under conditions of a toluene conversion of $18 \%$. Figure S6 shows catalyst conversion needs for over a 
20-hour-run time $\left(200^{\circ} \mathrm{C}\right)$. During the experiment, there was no significant change in the conversion rate, which indicated that the material maintained relatively good stability and durability during the whole process [44].

\section{Conclusions}

Pd@UIO-66 was prepared by the double-solvent method to study the effect of different Pd loading concentrations on the catalytic performance of toluene. The results show that $0.2 \%$ Pd@UIO-66 has the best performance, which is attributed to its large specific surface, high dispersion of Pd, and abundant adsorption oxygen. Furthermore, there is a strong electronic interaction between the unsaturated $\mathrm{Zr}-\mathrm{O}$ bond and Pd in UIO-66, which promotes the electron transfer of the carrier and the active component and increases the activity of $\mathrm{Pd}$, while the high concentration of elemental palladium toluene adsorption and decomposition also play an important role. Together with these factors, $0.2 \% \mathrm{Pd} @ U$ UO- 66 exhibits excellent low temperature catalytic ability.

Supplementary Materials: The following are available online at http://www.mdpi.com/1996-1944/13/1/88/s1, Scheme S1: Schematic diagram of catalytic process: 1. Air compressor 2. Reducing valve 3. Dry pipe 4 . Flowmeter 5. Injection pump 6. Hot plate 7. Gas evaporator 8. Thermostatic water tank 9. Buffer bottle 10. Three-way valve 11. Sorbent tube 12. Control valve 13. Reaction generator 14. Gas chromatograph 15. Glass tube, Figure S1: XPS spectra of Zr3d, Figure S2: N2 adsorption/desorption analysis of UIO-66, Figure S3: Toluene conversion of UIO-66, Figure S4: XRD pattern of the sample before and after the reaction, (a) UIO-66 (b) $0.2 \%$ Pd@U before reaction (c) $0.2 \% \mathrm{Pd} @ U$ after reaction, Figure S5: FTIR spectra of (a) UIO-66, (b) 0.2\% Pd@U before reaction and (c) $0.2 \%$ Pd@U after reaction, Figure S6: Long-term activity test for $0.2 \%$ Pd@U, Table S1: The Pd content and BET of all sample, Table S2: XPS data of the sample, Table S3: Catalytic Activities and apparent activation energies (Ea) of the four samples.

Author Contributions: Conceptualization and methodology, C.W. and M.L.; formal analysis, investigation, and data curation H.H., C.W. and E.W.; writing - original draft preparation, C.W.; writing-review and editing, M.L., C.W., H.H. and E.W. All authors have read and agreed to the published version of the manuscript.

Funding: This project was supported financially by the National Natural Science Foundation of China (no. 51672040), Science and Technology Research Projects of the Education Department of Jilin Province (no. JJKH20180429KJ) and Jilin City Science and Technology Bureau (no. 201750228).

Conflicts of Interest: The authors declare no conflict of interest.

\section{References}

1. Zhao, L.; Zhang, Z.; Li, Y.; Leng, X.; Zhang, T.; Yuan, F.; Niu, X.; Zhu, Y. Synthesis of CeaMnO microsphere with hierarchical structure and its excellent catalytic performance for toluene combustion. Appl. Catal. B Environ. 2019, 245, 502-512. [CrossRef]

2. Chen, J.; Chen, X.; Xu, Z.; Xu, W.J.; Li, J.J.; Jia, H.P.; Chen, J. Syntheses of Hierarchical $\mathrm{MnO}_{2} \mathrm{viaH}_{2} \mathrm{O}_{2}$ Selectively Reducing $\mathrm{KMnO}_{4}$ for Catalytic Combustion of Toluene. ChemistrySelect 2016, 1, 4052-4056. [CrossRef]

3. Mo, S.; Zhang, Q.; Ren, Q.; Xiong, J.; Zhang, M.; Feng, Z.; Yan, D.; Fu, M.; Wu, J.; Chen, L.; et al. Leaf-like Co-ZIF-L derivatives embedded on $\mathrm{Co}_{2} \mathrm{AlO}_{4} / \mathrm{Ni}$ foam from hydrotalcites as monolithic catalysts for toluene abatement. J. Hazard. Mater. 2019, 364, 571-580. [CrossRef] [PubMed]

4. Luo, Y.; Zheng, Y.; Zuo, J.; Feng, X.; Wang, X.; Zhang, T.; Zhang, K.; Jiang, L. Insights into the high performance of Mn-Co oxides derived from metal-organic frameworks for total toluene oxidation. J. Hazard. Mater. 2018, 349, 119-127. [CrossRef] [PubMed]

5. Yang, X.; Yu, X.; Jing, M.; Song, W.; Liu, J.; Ge, M. Defective $\mathrm{Mn}_{\mathrm{x}} \mathrm{Zr}_{1}-\mathrm{xO}_{2}$ solid solution for the catalytic oxidation of toluene: Insights into the oxygen vacancy contribution. ACS Appl. Mater. Interfaces 2018, 11, 730-739. [CrossRef] [PubMed]

6. da Silva, A.G.M.; Fajardo, H.V.; Balzer, R.; Probst, L.F.; Prado, N.T.; Camargo, P.H.; Robles-Dutenhefner, P.A. Efficient ceria-silica catalysts for BTX oxidation: Probing the catalytic performance and oxygen storage. Chem. Eng. J. 2016, 286, 369-376. [CrossRef]

7. Tan, W.; Deng, J.; Xie, S.; Yang, H.; Jiang, Y.; Guo, G.; Dai, H. $\mathrm{Ce}_{(0.6)} \mathrm{Zr}_{(0.3)} \mathrm{Y}_{(0.1)} \mathrm{O}_{(2)}$ nanorod supported gold and palladium alloy nanoparticles: High-performance catalysts for toluene oxidation. Nanoscale 2015, 7, 8510-8523. [CrossRef] 
8. Kim, S.C.; Shim, W.G. Catalytic combustion of VOCs over a series of manganese oxide catalysts. Appl. Catal. B Environ. 2010, 98, 180-185. [CrossRef]

9. Jahromi, H.; Agblevor, F.A. Hydrotreating of guaiacol: A comparative study of Red mud-supported nickel and commercial Ni/SiO${ }_{2}-\mathrm{Al}_{2} \mathrm{O}_{3}$ catalysts. Appl. Catal. A Gen. 2018, 558, 109-121. [CrossRef]

10. Shen, Z.; He, P.; Wang, A.; Harrhy, J.; Meng, S.; Peng, H.; Song, H. Conversion of naphthalene as model compound of polyaromatics to mono-aromatic hydrocarbons under the mixed hydrogen and methane atmosphere. Fuel 2019, 243, 469-477. [CrossRef]

11. Kamal, M.S.; Razzak, S.A.; Hossain, M.M. Catalytic oxidation of volatile organic compounds (VOCs)—A review. Atmos. Environ. 2016, 140, 117-134. [CrossRef]

12. Masui, T.; Imadzu, H.; Matsuyama, N.; Imanaka, N. Total oxidation of toluene on $\mathrm{Pt} / \mathrm{CeO}_{2}-\mathrm{ZrO}_{2}-\mathrm{Bi}_{2} \mathrm{O}_{3} /$ gamma- $\mathrm{Al}_{2} \mathrm{O}_{3}$ catalysts prepared in the presence of polyvinyl pyrrolidone. J. Hazard. Mater. 2010, 176, 1106-1109. [CrossRef] [PubMed]

13. He, C.; Shen, Q.; Liu, M. Toluene destruction over nanometric palladium supported ZSM-5 catalysts: Influences of support acidity and operation condition. J. Porous Mater. 2014, 21, 551-563. [CrossRef]

14. Okumura, K.; Kobayashi, T.; Tanaka, H.; Niwa, M. Toluene combustion over palladium supported on various metal oxide supports. Appl. Catal. B Environ. 2003, 44, 325-331. [CrossRef]

15. Bychkov, V.Y.; Tyulenin, Y.P.; Gorenberg, A.Y.; Sokolov, S.; Korchak, V.N. Evolution of Pd catalyst structure and activity during catalytic oxidation of methane and ethane. Appl. Catal. A Gen. 2014, 485, 1-9. [CrossRef]

16. Barakat, T.; Rooke, J.; Cousin, R.; Lamonier, J.F.; Giraudon, J.M.; Su, B.L.; Siffert, S. Investigation of the elimination of VOC mixtures over a Pd-loaded V-doped $\mathrm{TiO}_{2}$ support. New J. Chem. 2014, 38, 2066-2074. [CrossRef]

17. He, C.; Zhang, F.; Yue, L.; Shang, X.; Chen, J.; Hao, Z. Nanometric palladium confined in mesoporous silica as efficient catalysts for toluene oxidation at low temperature. Appl. Catal. B Environ. 2012, 111, 46-57. [CrossRef]

18. Wang, H.; Yang, W.; Tian, P.; Zhou, J.; Tang, R.; Wu, S. A highly active and anti-coking Pd-Pt/SiO 2 catalyst for catalytic combustion of toluene at low temperature. Appl. Catal. A Gen. 2017, 529, 60-67. [CrossRef]

19. Yue, L.; He, C.; Zhang, X.; Li, P.; Wang, Z.; Wang, H.; Hao, Z. Catalytic behavior and reaction routes of MEK oxidation over Pd/ZSM-5 and Pd-Ce/ZSM-5 catalysts. J. Hazard. Mater. 2013, 244, 613-620. [CrossRef]

20. Huang, S.; Zhang, C.; He, H. Effect of pretreatment on $\mathrm{Pd} / \mathrm{Al}_{2} \mathrm{O}_{3}$ catalyst for catalytic oxidation of o-xylene at low temperature. J. Environ. Sci. 2013, 25, 1206-1212. [CrossRef]

21. Saqer, S.M.; Kondarides, D.I.; Verykios, X.E. Catalytic Activity of Supported Platinum and Metal Oxide Catalysts for Toluene Oxidation. Top. Catal. 2009, 52, 517-527. [CrossRef]

22. Jiang, H.L.; Akita, T.; Ishida, T.; Haruta, M.; Xu, Q. Synergistic catalysis of Au@Ag core-shell nanoparticles stabilized on metal-organic framework. J. Am. Chem. Soc. 2011, 133, 1304-1306. [CrossRef] [PubMed]

23. Jiang, D.; Fang, G.; Tong, Y.; Wu, X.; Wang, Y.; Hong, D.; Leng, W.; Liang, Z.; Tu, P.; Liu, L.; et al. Multifunctional Pd@UiO-66 Catalysts for Continuous Catalytic Upgrading of Ethanol to n-Butanol. ACS Catal. 2018, 8, 11973-11978. [CrossRef]

24. Na, K.; Choi, K.M.; Yaghi, O.M.; Somorjai, G.A. Metal nanocrystals embedded in single nanocrystals of MOFs give unusual selectivity as heterogeneous catalysts. Nano Lett. 2014, 14, 5979-5983. [CrossRef] [PubMed]

25. Chen, B.; Ockwig, N.W.; Millward, A.R.; Contreras, D.S.; Yaghi, O.M. High $\mathrm{H}_{2}$ adsorption in a microporous metal-organic framework with open metal sites. Angew. Chem. Int. Ed. Engl. 2005, 44, 4745-4749. [CrossRef] [PubMed]

26. Yang, Q.; Chen, Y.Z.; Wang, Z.U.; Xu, Q.; Jiang, H.L. One-pot tandem catalysis over Pd@MIL-101: Boosting the efficiency of nitro compound hydrogenation by coupling with ammonia borane dehydrogenation. Chem. Commun. 2015, 51, 10419-10422. [CrossRef] [PubMed]

27. Dong, W.; Feng, C.; Zhang, L.; Shang, N.; Gao, S.; Wang, C.; Wang, Z. Pd@UiO-66: An Efficient Catalyst for Suzuki-Miyaura Coupling Reaction at Mild Condition. Catal. Lett. 2015, 146, 117-125. [CrossRef]

28. Luz, I.; Rösler, C.; Epp, K.; Llabrés i Xamena, F.X.; Fischer, R.A. Pd@UiO-66-Type MOFs Prepared by Chemical Vapor Infiltration as Shape-Selective Hydrogenation Catalysts. Eur. J. Inorg. Chem. 2015, 2015, 3904-3912. [CrossRef]

29. Aijaz, A.; Karkamkar, A.; Choi, Y.J.; Tsumori, N.; Ronnebro, E.; Autrey, T.; Shioyama, H.; Xu, Q. Immobilizing highly catalytically active $\mathrm{Pt}$ nanoparticles inside the pores of metal-organic framework: A double solvents approach. J. Am. Chem. Soc. 2012, 134, 13926-13929. [CrossRef] 
30. Wu, H.; Chua, Y.S.; Krungleviciute, V.; Tyagi, M.; Chen, P.; Yildirim, T.; Zhou, W. Unusual and highly tunable missing-linker defects in zirconium metal-organic framework UiO-66 and their important effects on gas adsorption. J. Am. Chem. Soc. 2013, 135, 10525-10532. [CrossRef]

31. Bedia, J.; Rosas, J.M.; Rodríguez-Mirasol, J.; Cordero, T. Pd supported on mesoporous activated carbons with high oxidation resistance as catalysts for toluene oxidation. Appl. Catal. B Environ. 2010, 94, 8-18. [CrossRef]

32. Chen, L.; Gao, Z.; Li, Y. Immobilization of $\mathrm{Pd}(\mathrm{II})$ on MOFs as a highly active heterogeneous catalyst for Suzuki-Miyaura and Ullmann-type coupling reactions. Catal. Today 2015, 245, 122-128. [CrossRef]

33. Taylor, M.N.; Zhou, W.; Garcia, T.; Solsona, B.; Carley, A.F.; Kiely, C.J.; Taylor, S.H. Synergy between tungsten and palladium supported on titania for the catalytic total oxidation of propane. J. Catal. 2012, 285, 103-114. [CrossRef]

34. Jasmina Hafizovic, C.; Jakobsen, S.; Unni, O.; Nathalie, G.; Carlo, L.; Silvia, B.; Karl Petter, L. A new zirconium inorganic building brick forming metal organic frameworks with exceptional stability. J. Am. Chem. Soc. 2008, 130, 13850-13851.

35. Bulushev, D.A.; Bulusheva, L.G.; Beloshapkin, S.; O'Connor, T.; Okotrub, A.V.; Ryan, K.M. Pd Clusters Supported on Amorphous, Low-Porosity Carbon Spheres for Hydrogen Production from Formic Acid. ACS Appl. Mater. Interfaces 2015, 7, 8719-8726. [CrossRef]

36. Xie, S.; Liu, Y.; Deng, J.; Zhao, X.; Yang, J.; Zhang, K.; Zhuo, H.; Arandiyan, H.; Dai, H. Effect of transition metal doping on the catalytic performance of $\mathrm{Au}-\mathrm{Pd} / 3 \mathrm{DOM} \mathrm{Mn}_{2} \mathrm{O}_{3}$ for the oxidation of methane and o-xylene. Appl. Catal. B Environ. 2017, 206, 221-232. [CrossRef]

37. Shen, Z.; Hu, F.; Li, J. Hierarchical Core-Shell $\mathrm{Al}_{2} \mathrm{O}_{3} @ \mathrm{Pd}-\mathrm{CoAlO}$ Microspheres for Low-Temperature Toluene Combustion. ACS Catal. 2016, 6, 3433-3441.

38. Yuan, L.; Hung, S.F.; Tang, Z.R.; Chen, H.M.; Xiong, Y.; Xu, Y.J. Dynamic Evolution of Atomically Dispersed $\mathrm{Cu}$ Species for $\mathrm{CO}_{2}$ Photoreduction to Solar Fuels. ACS Catal. 2019, 9, 4824-4833. [CrossRef]

39. Tidahy, H.L.; Hosseni, M.; Siffert, S.; Cousin, R.; Lamonier, J.F.; Aboukaïs, A.; Su, B.L.; Giraudon, J.M.; Leclercq, G. Nanostructured macro-mesoporous zirconia impregnated by noble metal for catalytic total oxidation of toluene. Catal. Today 2008, 137, 335-339. [CrossRef]

40. Hosseini, M.; Barakat, T.; Cousin, R.; Aboukaïs, A.; Su, B.L.; De Weireld, G.; Siffert, S. Catalytic performance of core-shell and alloy $\mathrm{Pd}-\mathrm{Au}$ nanoparticles for total oxidation of VOC: The effect of metal deposition. Appl. Catal. B Environ. 2012, 111, 218-224. [CrossRef]

41. Abdel-Mageed, A.M.; Rungtaweevoranit, B.; Parlinska-Wojtan, M.; Pei, X.; Yaghi, O.M.; Behm, R.J. Highly Active and Stable Single-Atom Cu Catalysts Supported by a Metal-Organic Framework. J. Am. Chem. Soc. 2019, 141, 5201-5210. [CrossRef] [PubMed]

42. Tsumori, N.; Chen, L.; Wang, Q.; Zhu, Q.L.; Kitta, M.; Xu, Q. Quasi-MOF: Exposing Inorganic Nodes to Guest Metal Nanoparticles for Drastically Enhanced Catalytic Activity. Chem 2018, 4, 845-856. [CrossRef]

43. Fan, L.; Zhao, F.; Huang, Z.; Chen, B.; Zhou, S.F.; Zhan, G. Partial deligandation of M/Ce-BTC nanorods (M = $\mathrm{Au}, \mathrm{Cu}, \mathrm{au}-\mathrm{cu}$ ) with "Quasi-MOF” structures towards improving catalytic activity and stability. Appl. Catal. A Gen. 2019, 572, 34-43. [CrossRef]

44. Li, B.; Yang, Q.; Peng, Y.; Chen, J.; Deng, L.; Wang, D.; Hong, X.; Li, J. Enhanced low-temperature activity of $\mathrm{LaMnO}_{3}$ for toluene oxidation: The effect of treatment with an acidic $\mathrm{KMnO}_{4}$. Chem. Eng. J. 2019, 366, 92-99. [CrossRef]

(C) 2019 by the authors. Licensee MDPI, Basel, Switzerland. This article is an open access article distributed under the terms and conditions of the Creative Commons Attribution (CC BY) license (http://creativecommons.org/licenses/by/4.0/). 